\title{
The Grammaticalization of Aspectual Auxiliary Verbs in Korean
}

\author{
Hae-Yun Lee
}

\begin{abstract}
General verbs in many languages show some stages of grammaticalization: verb > auxiliary verb > clitics > affix. If we restrict ourselves to the transition from verbs to auxiliary verbs, we can notice some intermediate stages of grammaticalization. In Korean, it is known that some verbs have undergone the grammaticalization which concerns with aspect. But it is unclear which aspect each verb is related with. In this paper we we show that some verbs are related with Aktionsarten and other verbs with aspect, assuming that aspectualities are divided into Aktionsarten such as state, process, accomplishment and achievement, and aspects such as Perfective and Imperfective. Especially we present the analyses of complex sentences, where more than one auxiliary verb appear.
\end{abstract}

Index Terms-Grammaticalization, auxiliary verbs, Aktionsart, aspect.

\section{INTRODUCTION}

Some verbs in many languages have undergone the grammaticalization. We can identify those phenomena in Korean as well as in English. Especially it is unclear which verbs are related with which aspects, because the concept 'aspect' is diverse according to the theories. In this talk we will show that some verbs are related with Aktionsarten of [1] and other verbs with aspect of [2], assuming that aspectualities are divided into Aktionsart such as state, activity, accomplishment and achievement, and aspects such as Perfective and Imperfective.

First, we will review various views about the grammaticalization on auxiliary verbs. Next, we will make the analyses of Korean auxiliary verbs from the viewpoint of some theories of grammaticalization. Especially we deal with some complex sentences, where more than one auxiliary verb appear.

\section{GRAMMATICALIZATION}

There are a few principles that researchers have found with respect to grammaticalization. In this section we will review some principles relevant to auxiliary verbs.

Ref. [3] proposed the following stages of grammaticalization called 'cline of grammaticality':

1) a. content item > grammatical word > clitic > inflectional affix

b. full verb > auxiliary > verbal clitic > verbal affix

Manuscript received October 29, 2014; revised May 13, 2015. This work was supported by Hankuk University of Foreign Studies Research Fund 2014.

Hae-Yun Lee is with the Linguistics \& Cognitive Science Department, Hankuk University of Foreign Studies, Yongin, Korea (e-mail: haeyun@hufs.ac.kr).
If we restrict ourselves to the transition from verbs to auxiliary verbs, the schema 1a) is changed into the schema 1b). We can see the examples of each stage in many languages, as in 2).

2) a. I have a book.

b. I have had a book.

c. We've built a new garage.

d. ils parleront. fr. 'they will speak'

We see the different categories of a verb have in 2): a full verb in 2a), an auxiliary verb in $2 b$ ), and a clitic in $2 c$ ). In addition, the French example $2 \mathrm{~d}$ ) show the use of an affix.

Each stage in the schema 1) is not clear cut, but can be overlapped. This view is reflected in the following process suggested in [4]:

- There is a linguistic structure A.

- A acquires a second structure B in specific contexts (A/B).

- In some other context, $\mathrm{A}$ is lost, with the effect that there is only B.

That is, there are 3 stages from a lexical verb to an auxiliary verb. Structures A and B may each go their own ways and continue to coexist as divergent reflexes of a historically single form over many centuries. After that, the structure B wins the structure A. We can identify each stage of the above process in the following example.

3) a. John is going to town soon.

b. John is going to work soon.

c. John is going to/gonna get sick soon.

The verb $g o$ is used as a pure lexical verb in 3a), and the verb $g o$ in 3b) can be used as an auxiliary verb if the word work is a verb, not a noun. Lastly the verb in 3c) can only be interpreted as an auxiliary verb marking future tense and can be reduced phonologically.

Let us focus on auxiliary verbs. [5] presents the auxiliation process as follows. The process starts from the form of $\mathrm{V}-\mathrm{V} 1$, where V is a nonfinite verb and V1 is a main verb. During the process, $\mathrm{V}$ loses its original content and instead gets grammatical functions.

- There is a lexical verb (V1) taking a non-finite verb as a complement (C).

- In specific contexts, V1 can be interpreted as a lexical verb or as expressing a grammatical function relating to TAM, and $\mathrm{C}$ has the function of a complement or of a new main verb.

- In certain other contexts, V1 expresses exclusively the grammatical function, and $\mathrm{C}$ that of the new main verb.

- The use of the grammatical function is generalized, and $\mathrm{C}$ can only be understood as the main verb whenever there is a non-finite verb as a complement.

The characteristics of grammaticalization in the above process can be summarized by phonetic, morphosyntactic, 
and semantic properties as follows:

- desemanticization: V1 loses most or all of its lexical semantics

- decategorialization: V1 loses salient morphosyntactic properties of a verb

- erosion: V1 tends to be phonetically reduced.

We see some examples in 4), where a sentence with a main verb and a sentence with its corresponding auxiliary verb are compared.

4) a. He kept all the money. vs. He kept complaining.

b. He used all the money. vs.

He used to come on Tuesdays.

c. He has all the money. vs. He has to pay.

The first sentence shows the use of a main verb, whereas the second sentence shows the use of an auxiliary verb.

As for lexical verbs grammaricalised into auxiliary verbs, [4] presented some schemas that are responsible for the grammatical categories of Tense and Aspect. Among them, the following three schemas are used more frequently:

- Location: " $\mathrm{X}$ is at $\mathrm{Y}$ "

- Motion: "X moves to/from Y"

- Action: "X does Y"

English verbs such as 'be' or 'have' are typical examples for the grammaticalization of auxiliary verbs (Fig. 1). We see more concrete stages from main verbs to auxiliary verbs in [6].

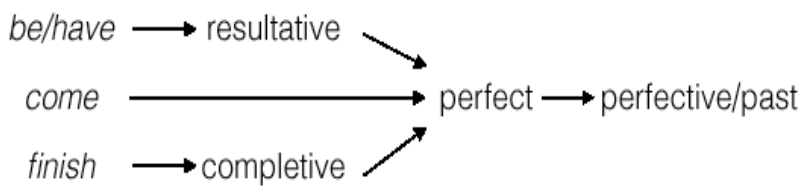

Fig. 1. Grammaticalization of perfective and past.

The diagram shows the paths of development leading to simple past and perfective. That is, auxiliaries from stative verbs (be, have) go through a resultative stage while auxiliaries from dynamic verbs (finish) go through a completive stage. Next the resultative or completive lead to perfect that then leads to perfective or simple past. The following shows the examples of the grammaticalization.

5) a. He is gone.

b. fadesó mbi ça va awe.

now 1.s recover finish

'Now I am completely recovered.' SANGO

c. He wœs gecumen. OE 'He was come'

The verb go in 5a) represents resultative, the verb finish in $5 b)$ completive. But we see the change from resultative into perfective in old English 5c).

Especially [7] divided Perfect verbs into 4 groups according to the original verbs participating in auxiliation, as below:

- copula + past participle: Hindi, Tamil, ...

- have + past participle: Germanic, Romance, ...

- verb + particle already: Kwa, ...

- finish, throw away: Sango, Ewe, Korean, ...

As we see above, Germanic languages including English belong to type II, where a possession verb have is used in Perfect construction. Korean belongs to type IV, where various action verbs including throw away are used. In the next section, we see the grammaticalization of Korean auxiliary verbs in details.

\section{KOREAN AUXILIARY VERBS}

Korean has a category called 'auxiliary predicate' which comprises verbs and adjectives. According to the examination of the Sejong Corpus (ca. 10 million words), Korean has 55 auxiliary predicates whose frequency is over 6 . The following Table I shows some predicates with high frequency.

TABLE I: THE LIST OF KOREAN AUXILIARY PREDICATES

\begin{tabular}{llllll}
\hline \hline & $\begin{array}{l}\text { Aux. } \\
\text { pred. }\end{array}$ & Freq. & & $\begin{array}{l}\text { Aux. } \\
\text { pred. }\end{array}$ & Freq. \\
\hline 1 & iss- & 159,283 & 11 & peli- & 11,639 \\
2 & ha- & 98,701 & 12 & noh- & 10,497 \\
3 & anh- & 83,075 & 13 & mal- & 10,212 \\
4 & ci- & 48,880 & 14 & nay- & 9,318 \\
5 & cu- & 36,563 & 15 & naka- & 5,362 \\
6 & po- & 29,692 & 16 & tu- & 4,908 \\
7 & mocha- & 22,381 & 17 & na- & 4,685 \\
8 & o- & 19,631 & 18 & tay- & 2,784 \\
9 & sip- & 14,183 & 19 & tal- & 2,333 \\
10 & ka- & 13,948 & 20 & tul- & 2,125 \\
\hline \hline
\end{tabular}

Korean belongs to the type SOV. So the auxiliary predicate appears at the end of a sentence, and a main verb appears before the auxiliary predicate. Most of grammatical functions are marked at the auxiliary predicate. The following shows some examples:

6) a. John-i cip-ul ttena-ass-ta.

John-nom house-acc leave-past-decl

'John left the house.'

b. John-i cip-ul ttena-e peli-ess-ta.

John-nom house-acc leave-conn aux-past-decl

'John has left the house.'

In a sentence 6a) without an auxiliary predicate, the grammatical functions such as tense and mood are marked at the main verb. Otherwise we see the grammatical functions attached at the auxiliary predicate peli in the sentence 6b). In addition, the main verb in the latter always appears together with a affix $e$ that connects the main verb with the auxiliary verb.

\section{A. Data}

As for the grammatical functions of auxiliary predicates, we can identify their various functions in 7): aspect in 7a), modality in $7 \mathrm{~b}$ ), causative in $7 \mathrm{c}$ ), passive in $7 \mathrm{~d}$ ), and negation in $7 \mathrm{e})$. In this paper, we will focus on the auxiliary predicates representing aspect like 7a).

7) a. ku-nun phyenci-lul ssu-ko iss-ta.

he-nom letter-acc write-conn be-dec

'He is writing a letter.'

b. ku-nun kenkang ha-e poin-ta.

he-nom healthy do-conn look-dec

'He looks like healthy.'

c. emma-ka ai-eykey os-ul ip-key $h a$-ess-ta.

Mamma-nom child-dat clothes-acc

put-on-conn do-past-dec

'Mamma had the child put on the clothes.'

d. na-nun mikuk-ulo ka-key toy-ess-ta.

I-nom USA-dir go-conn become-past-dec

'I was passed to USA.'

e. na-nun ul-ci anh-nun-ta.

I-nom cry-conn not-pres-dec 
'I don't cry.'

Before we go into the grammaticalization of auxiliary predicates, we must clarify some concepts related with aspect.

\section{B. Aspectuality}

We adapt the concept 'aspectuality' in the sense of [8]. According to him, aspectuality is divided into Aktionsart and aspect. The latter encodes if the event represented by a predicate is considered as a whole event or as a part of it. The former represents the way the event is developed. Normally the definition of [1] has been accepted with respect to the concept 'Aktionsart'. Table II shows the classification of Aktionsart: state, activity, accomplishment, achievement. And below the table, we see a typical example for each Aktionsart.

TABLE II: CLASSIFICATION OF AKTIONSART

\begin{tabular}{llll}
\hline \hline & dynamic & durative & telic \\
\hline state & - & + & $+/-$ \\
activity & + & + & - \\
accomplishment & + & + & + \\
achievement & + & - & + \\
\hline \hline
\end{tabular}

8) a. She hated ice cream (state)

b. Your cat watched those birds (activity)

c. Her boss learned Korean (accomplishment)

d. The cease-fire began at noon yesterday (achievement)

As for Aspect, we adapt the classification of [2]. According to him, Aspect is divided into Perfective and Imperfective. The latter comprises the concept 'Progressive' which we are familiar with in English (see Fig. 2).

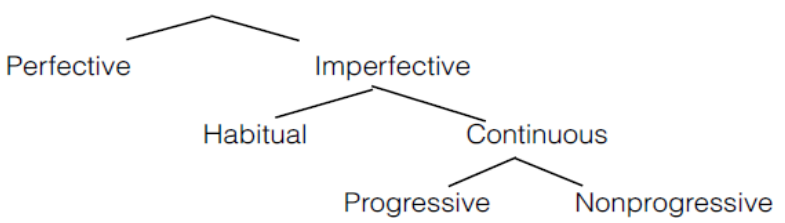

Fig. 2. Classification of aspect.

Perfective presents an event in summary, viewed as a whole from the outside, without regard for the internal structure of the event. The Perfective is distinguished from the Imperfective, which presents an event as having internal structure such as ongoing or habitual actions. The Russian examples in 9) show the difference between Perfective and Imperfective, and the English examples in 10) show the difference between Progressive and Habitual.

9) а. чита́ть

'to read'

b. прочита́ть

'to have read'

10) a. John was walking.

b. John used to work here.

Now we assume that a sentence represents one aspect and one Aktionsart. Furthrmore there will be some restrictions on the combination of aspect and Aktionsart. Following [9], we assume that an Aspect require a specific Aktionsart as an input. For example, Perfective in 11) requires Achievement verb as an input, and Progressive in 12) requires Activity as an input.

11) a. Harry has reached the top. b. *The star has twinkled.

12) a. The president is speaking.

b. Harry is hiccupping.

If we express the relations by means of function, we can represent those relations as follows:

13) a. $f($ achievement $)=$ perfective

b. $\mathrm{f}($ activity $)=$ progressive

Below we will make an analysis of Korean auxiliary verbs by means of the functional representation (13).

\section{Constructions}

From the viewpoint of constructions, it was insisted that Korean auxiliary verbs are developed through serial verbs from two lexical verbs.

14) a. sunhuy-nun sakwa-lul kkak-a emma-wa sunhuy-nom apple-acc peel-conn mamma-com hamkkey mek-ess-ta. together eat-past-dec 'sunhuy peeled apples and ate them with her mother together.'

b. sunhuy-nun sakwa-lul kkak-a mek-ess-ta. 'sunhuy peeled and ate apples.'

c. sunhuy-nun sakwa-lul phal-a mek-ess-ta. 'sunhuy has sold apples out.'

In the clause chain construction 14a), two successive events are reported in the form of a composite sentence. Next, the clause chain construction can be changed into a simple sentence where a serial verb appears instead of two independent verbs, as we see in 14b). The serial verb construction reports on event by the second verb, with representing the manner of the event or action by the first verb. Next, the second verb is used more frequently. So its meaning has been generalized and has lost its original lexical meaning. As a result, the second verb becomes an auxiliary verb in 14c).

The examples in 15)-17) show some pair of a main verb and its corresponding auxiliary verb carrying the function of aspectualities.

15) a. ku-nun ssuleykitong-ey hyuci-lul peli-ess-ta. he-nom wastebasket-in garbage-acc dump-past-dec 'He dumped garbage into the wastebasket.'

b. ku-nun pap-ul mek-e peli-ess-ta. he-nom meal-acc eat-conn aux-past-dec 'He has eaten a meal.'

16) a. chelsu-nun cip-ulo $k a$-n-ta. chelsu-nom hause-dir go-pres-dec 'chelsu goes home.'

b. pyengsa-tul-I cuk-e $k a$-n-ta soldier-plu-nom die-conn aux-pres-dec 'Soldiers are dying.'

17) a. chelsu-ka pang-ey iss-ta. chelsu-nom room-loc be-dec 'chelsu is in the room.'

b. kkoch-i phi-e iss-ta. flower-nom bloom-conn aux-dec 'Flowers bloom.'

At the next section, we will see which concrete function the auxiliary verb is responsible for.

\section{Grammaticalization}

There have been some debates about the classification of aspectual auxiliary verbs within the Korean Linguistics. We 
follow the classification of [10], where auxiliary predicates are divided into the one group related with Aspect and the other group related with Aktionsart. As for Aspect, -ko iss represents Progressive in 18a). - $e$ iss and another -ko iss represent Perfective in 18b). For the Perfective there is also specially an affix -ess- that expresses past tense, and that is grammaticalized from the Perfective auxiliary predicate $-e$ iss- in 19).

18) a. chelsu-ka ppang-ul mek-ko iss-ta.

chelsu-nom bread-acc eat-conn aux-dec

'chelsu is eating breads.'

b. chelsu-ka chimtay-ey nu-e iss-ta.

chelsu-nom bed-at lie-conn aux-dec

'chelsu has lied on the bed.'

chelsu-ka ppang-ul mek-ess-ta.

chelsu-nom bread-acc eat-past-dec

'chelsu has eaten breads.'

The rest of auxiliary verbs are assumed to be responsible for the Aktionsart. For example, the verbs $-e k a$ and $-e o$ represent process in 20). The verbs such as $-e t u$, $-e$ peli, $-e$ noh,-e nay, -ko mal, etc. represent achievement in 21).

19) a. chelsu-ka ppang-ul ta mek-e $k a$-n-ta.

chelsu-nom bread-acc all eat-conn aux-pres-dec

'chelsu is eating all the bread.'

b. cemcem nal-i palk-a $o$-n-ta. gradually day-nom bright-conn aux-pres-dec. 'Gradually dawn is breaking.'

20) a. chelsu-ka ppang-ul ta mek-e peli-ess-ta. chelsu-nom bread-acc all eat-conn aux-past-dec 'chelsu has eaten all the bread.'

b. ku-ka chayk-ul chayksang wi-ey enc-e tu-ess-ta. he-nom book-acc table-on put-conn aux-past-dec 'He has put the book on the table.'

c. ku-nun apeci-uy helak-ul he-nom father-gen permission-acc et-e nay-ess-ta. get-conn aux-past-dec

'He has got permission from his father.'

d. hoyhap-i penpeni kyellyetoy-ko mal-ass-ta. meeting-nom often break-conn aux-past-dec 'Meetings has often broken down.'

Now let us see how we can explain the sentences that contain some grammaticalized auxiliary verbs. Let us start with the following examples, where only one auxiliary verb appears.

21) a. chelsu-ka ppang-ul mek-ko iss-ta.

chelsu-nom bread-acc eat-conn aux-dec

'chelsu is eating breads.'

b. chelsu-ka ppang-ul mek-e peli-ess-ta.

chelsu-nom bread-acc eat-conn aux-past-dec

'chelsu has eaten breads.'

The examples (22) have one main verb and one auxiliary verb respectively. The sentence (22a) represents Activity by the main verb mek- and Progressive by the auxiliary verb - ko iss-. But the sentence (22b) represents Achievement by the combination of a main verb and an auxiliary verb mek-e peliand Perfective by an affix -ess that marks past tense originally. Owing to the auxiliary verb peli-, the Aktionsart of the main verb Activity changes into Achievement.

To sum up, we can say that aspect Progressive requires an Aktionsart Activity as its input and that aspect Perfective requires an Aktionsart Achievement as its input. Therefore we can represent each process of the explanations as follows.

22) a. $f_{\text {iss }}$ (activity) $=$ progressive

b. $\mathrm{f}_{\text {peli }}(\mathrm{x})=$ achievement

$\mathrm{f}_{\text {ess }}($ achievement $)=$ perfective

Especially the example 22b) is explained by the application of two functions in $23 \mathrm{~b}$ ), i.e. a composite function $\mathrm{f}_{\text {ess }} \bullet \mathrm{f}_{\text {peli }}$. This accords with the representation 13).

In the same way we can explain more complex examples, where more than two auxiliary verbs appear.

23) a. chelsu-ka manh-un ton-ul

chelsu-nom much-mod money-acc

pel-e $k a$-ko iss-ta.

earn-conn aux-conn aux-dec

'chelsu is making much money.'

b. chelsu-ka nunmul-ul ssot-e nay-ko

chelsu-nom tears-acc shed-conn aux-conn

mal-ass-ta.

aux-past-dec

'chelsu has shed tears.'

In 23a) the combination of a main verb and an auxiliary verb pel-e ka-ko represents Activity, where the original Aktionsart Accomplishment of the main verb pel-is changed by the auxiliary verb - $e k a$-. And the other auxiliary verb - $k o$ iss- represents the aspect Progressive. That process can be represented by the composite function $\mathrm{f}_{\mathrm{iss}} \cdot \mathrm{f}_{\mathrm{ka}}$ illustrated in 24).

24) $\mathrm{f}_{\mathrm{ka}}(\mathrm{x})=$ activity

$\mathrm{f}_{\text {iss }}($ activity $)=$ progressive

Next, let us turn into the example 23b). As for Aktionsart, the combination of a main verb ssot- and an auxiliary verb - $e$ nay- represents Achievement, where the original Aktionsart Accomplishment of the main verb ssot- is changed by the auxiliary verb - $e$ nay-. And the other auxiliary verb - ko malrepresents the aspect Perfective. We can represent the process as follows.

25) $f_{\text {nay }}(x)=$ achievement

$\mathrm{f}_{\text {mal }}(\mathrm{x})=$ achievement

$\mathrm{f}_{\text {ess }}($ achievement $)=$ perfective

That is, the aspect Perfective is resulted from the application of three functions in 25), i.e. the composite function $\mathrm{f}_{\text {ess }} \bullet \mathrm{f}_{\text {mal }} \mathrm{f}_{\text {ess }} \bullet \mathrm{f}_{\text {nay }}$. All the functional representations in 24) and 25) accord with the general representation 13).

\section{CONCLUSION}

In this paper, we presented the analyses of the sentences where auxiliary verbs appear. Our works are based on the following assumptions: Every sentence represents an aspect that manifests itself at auxiliary verbs or other lexical items. The lexical item which is responsible for an aspect requires a predicate with a specific Aktionsart. If a main predicate does not satisfy the requirement of the lexical items, an in-between auxiliary verb changes its Aktionsart like a functor. In the main part of the paper, we made an analysis of the complex sentences where more than one auxiliary verb appear in a sentence.

\section{REFERENCES}

[1] Z. Vendler, Linguistics in Philosophy, Ithaca, N.Y.: Cornell University Press, 1967. 
[2] B. Comrie, Aspect, Cambridge: Cambridge University Press, 1976.

[3] P. J. Hopper and E. C. Traugott, Grammaticalization, Cambridge, New York: Cambridge University Press, 2003.

[4] B. Heine, Auxiliaries: Cognitive Forces and Grammaticalization, Oxford: Oxford University Press, 1993.

[5] B. Heine and H. Narrog, "Grammaticalization and Linguistic Analysis," in the Oxford Handbook of Linguistic Analysis, B. Heine and H. Narrog, Eds. Oxford, New York: Oxford University Press, 2010, pp. 401-423.

[6] J. L. Bybee, R. Perkins, and W. Pagliuca, The Evolution of Grammar: Tense, Aspect and Modality in the Languages of the World, Chicago: University of Chicago Press, 1994.

[7] J. L. Bybee and Ö. Dahl, "The creation of tense and aspect systems in the languages of the world," Studies in Language, vol. 13, pp. 51-103, 1989.

[8] C. Smith, The Parameter of Aspect, Dordrecht: Kluwer, 1992.

[9] M. Moens and M. Steedman, "Temporal ontology and temporal reference," Computational Linguistics, vol. 14, pp. 15-28, 1988.
[10] C. Wu, "On the aspect of grammar on auxiliary verbs," Korean Linguistics, vol. 33, pp. 283-307, 2006.

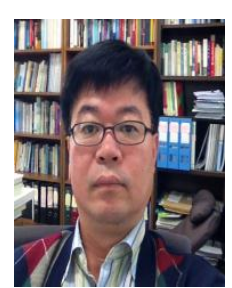

Hae-Yun Lee was born on November 20, 1966, in Iksan, Korea. He received the B.A. degree in German literature and language from Seoul National University, Korea, in 1988, the M.A. degree in German linguistics from Seoul National University, Korea, in 1990, and the Ph.D. degree in theoretical linguistics from the University of Munich, Germany, in 1998.

He was a visiting professor at the Korea Advanced Institute of Science and Technology, Korea. He is currently a professor at Hankuk University of Foreign Studies, Seoul, Korea. His research interests cover semantics, pragmatics, and computational semantics, with over 50 publications. 